Apresentação | Introduction

\title{
As biosseguranças e suas antropologias
}

\section{Biosecurities and their anthropologies}

\author{
Jean Segata* \\ * Universidade Federal do Rio Grande do Sul - Porto Alegre, RS, Brasil \\ jeansegata@gmail.com \\ https://orcid.org/0000-0002-2544-0745 \\ Andrea Mastrangelo** \\ ** Consejo Nacional de Investigaciones Científicas y Técnicas / \\ Universidad Nacional de San Martín - Buenos Aires, Argentina \\ andreaveronicamastrangelo@gmail.com \\ https://orcid.org/0000-0003-2844-6883
}


Biossegurança é um termo elástico. Ele começou a ganhar forma nos anos 1970 em referência a um conjunto de ações e de instruções voltadas a contenção de riscos inerentes à exposição a agentes biológicos potencialmente contaminantes. De início, estavam em cena os ambientes de atuação da emergente biotecnologia. Mas, à medida que seus produtos ganharam terreno fora dos ambientes controlados dos laboratórios, o seu escopo se expandiu em debates éticos, protocolos, processos e equipamentos laborais que passaram a ser empregados nos contextos hospitalares, na produção industrial, no comércio e demais segmentos que envolvem a manipulação genética e microbiológica (Neves et al., 2007). No entanto, esse processo coincidiu também com um conjunto de situações que se aceleraram na virada do século XXI e colocaram em relevo preocupações com o bioterrorismo, a segurança alimentar e a saúde global (Collier; Lakoff, 2008).

A chamada Guerra Fria e outros conflitos bélicos, sobretudo no Oriente Médio, acenderam especulações sobre o iminente uso de armas químicas em situações de bioterrorismo. Ao passo disso, os emergentes processos de globalização colocaram em relevo a biossegurança como um horizonte técnico para o controle de fronteiras, sejam elas biológicas ou de Estado-nação. Sob sua rubrica, passou-se a vigiar e controlar a circulação de agentes patógenos, como vírus e bactérias, mas também a acelerada circulação de pessoas e produtos de origem animal e vegetal. Assim, o debate sobre a segurança nacional, a pesquisa em saúde e suas crises, mas também os alimentos transgênicos, os organismos geneticamente modificados (GMO - genectic modified organism) e organismos vivos modificados (LMO - living modified organism) ${ }^{1}$ e as novas tecnologias para agricultura e pecuária, incorporaram a semântica e a atuação da biossegurança nas práticas cotidianas (Bingham; Hinchliffe, 2008; Fidler; Gostin, 2008).

O entendimento geral que orientou a organização deste número temático de Horizontes Antropológicos é que as políticas e práticas de biossegurança atravessam e emaranham domínios da economia, do direito, da saúde, da segurança e suas tecnologias e moralidades. Além disso, elas ecoam e intersectam os interesses de campos como o da biopolítica, das relações multiespécies ou da antropologia da ciência e da tecnologia. Resulta disso que os artigos

1 Ver http://www.fao.org/newsroom/es/news/2004/43684/index.html (acessado em 27/04/2020). 
reunidos neste volume não fecham questões, tampouco reivindicam esforços em torno da constituição de um novo e delimitado campo para a disciplina. Eles também não definem categorias, nem afirmam para ele teorias e métodos. Trata-se, antes, de um conjunto de esforços etnográficos que nos auxiliam a problematizar políticas e práticas que tendem a ecoar uma ideia global de biossegurança como horizonte comum que molda de forma discreta as experiências particulares. Emergem assim as tensões, a pluralidade de entendimentos e as perspectivas de crítica.

No primeiro artigo, "Febre a bordo", a antropóloga portuguesa Cristiana Bastos tematiza a intersecção entre as migrações laborais e a exposição às pestes, provocando o leitor a pensar a perturbadora sintonia entre biossegurança e necropolítica. Depois de uma longa trajetória de pesquisas sobre epidemias, com destaque ao HIV-Aids, à sífilis e suas conexões globais explicadas desde trânsitos que começam na medicina imperial, a autora explora neste artigo o relato de mais de 50 mortes infantis por sarampo numa viagem de emigrantes. A partir de uma etnografia histórica, Bastos segue os registros dos fluxos de trabalhadores portugueses, sobretudo ilhéus da Madeira e dos Açores, contratados para o trabalho nas lavouras de cana-de-açúcar da Guiana e do Havaí, na segunda metade do século XIX, para discutir questões problemáticas sobre saúde, desigualdade, tráfico, corpo, gênero e família e o modo como as materialidades dos navios amplificam seus efeitos negativos.

Além da brutalidade do trabalho nas lavouras de cana, o fantasma dos trópicos era desenhado por meio do assombro com as pestes. Desde o início da colonização, os europeus que aportavam nas Américas e no continente africano eram atingidos pela febre amarela e pela malária, muitas vezes de forma fatal. O próprio desenvolvimento da medicina tropical responderia, sobremaneira, como um saber médico desenvolvido para a aclimatação do branco às terras quentes (Löwy, 2006). Mas o que Bastos nos mostra é que o processo era ainda mais complexo, uma vez que as longas viagens, em si, já se convertiam em processos de adoecimento, marcados pela fome extrema e pelo frio congelante. A desnutrição, as diarreias e as febres, nas palavras da autora, convertiam os navios em "incubadoras de desumanização".

No ínterim das febres a bordo, sobretudo no caso de sarampo infantil discutido por Bastos, alguns paralelos com situações atuais do universo das epidemias são particularmente interessantes. Uma dessas situações tem sido mais 
imediatamente vividas no contexto da Covid-19 - o isolamento. Pandemias quase sempre têm sido explicadas pelos processos passivos de espalhamento de vírus e outros agentes patógenos por meio do comércio de produtos e circulação de pessoas (e de pessoas como produto de comércio). Nesse caso, o isolamento de navios que noticiavam febres e mortes a bordo era uma prática comum antes do seu aportamento. Esse processo visava a proteção de quem estivesse fora do navio, mas não garantia a "cura" e a saúde de quem estava no seu interior, em meio à situação de contaminação. Muitas vezes, além do sofrimento intrínseco ao confinamento, muitas das pessoas que não morriam em decorrência da doença morriam de fome ou de intoxicação pelo consumo de alimentos que, devido ao tempo, pereciam. A ideia de "sacrifício de uma minoria" (dentro do navio) "pelo bem da maioria" (fora dele) era costumeiramente acionada. No contexto da atual pandemia provocada pelo Sars-Cov-2 as ideias de quarentena, isolamento social, lockdown têm sido amplamente vivenciadas como medida de proteção e mitigação da doença. Contudo, a "escala do navio" mudou. Implementadas em praticamente todos os países atingidos, as medidas de isolamento têm colocado em relevo a persistência da necropolítica. Trata-se do escancaramento das estruturas de desigualdade. De um lado, elas favorecem a proteção à parcela da população, especialmente das camadas médias e altas, que tem condições de se manter em isolamento, com acesso remoto ao trabalho, à escola e a inúmeros serviços por meio de aplicativos, além da ampliada segurança de acesso a leitos hospitalares garantidos por planos privados de saúde. De outro, está a parcela da população que cronicamente vive exposta a riscos e à morte, sejam eles decorrentes das históricas cargas acumuladas de vulnerabilidade, como a pobreza, o racismo e a falta de acesso a direitos fundamentais, como também pela cada vez mais crescente precarização de suas relações de trabalho.

Outra situação discutida por Bastos em seu artigo é a de como, a despeito do sofrimento devastador da experiência da perda, as mães eram costumeiramente culpabilizadas pelo adoecimento e morte das crianças com sarampo nos navios. Os inquéritos sugeriam falta de cuidado com provisões de alimento e com vestimentas adequadas para suportar as intempéries. Desigualdades de gênero importam nas situações de epidemia, e a reflexão de Bastos, nesse caminho, ecoa os caminhos seguidos pelo governo brasileiro no cuidado com a zika. Como têm sido amplamente tematizado por Diniz (2016a, 2016b, 2017), 
as políticas de controle pesam contra a vida de mulheres, especialmente negras e pobres. Um episódio emblemático, protagonizado pelo então ministro da Saúde, Marcelo Castro, exemplifica (mas não esgota) essa questão. Em um pronunciamento, em 2016, ele disse que para se evitar a microcefalia - uma das manifestações da síndrome congênita do zika vírus - as mulheres não deveriam engravidar, e, se quisessem engravidar, deveriam, antes, contrair a zika para ficarem imunizadas e não serem atingidas pelo vírus durante a gestação. Pior que isso, ele ainda afirmou que só há microcefalia quando há bebê na barriga e, para evitar esta situação, as mulheres não deveriam andar com as pernas de fora. ${ }^{2}$ A polêmica declaração ecoava o patriarcalismo e o colonialismo de uma ampla e enraizada cultura do estupro e, quando criticado por esse tópico, o ministro ironizou a situação dizendo que fazia menção, na verdade, ao fato de que "com as pernas de fora o mosquito pica". O fato é que, como mostra Diniz (2016a, 2016b, 2017) em seus trabalhos, as mulheres, mães de crianças que desenvolveram a microcefalia, são pobres e negras na sua maioria, e, ao invés de culpadas pela doença, são elas também vítimas da falta de estruturas e de políticas de cuidado básico especializado, como também de suporte social, já que necessitam abandonar suas atividades profissionais para se converterem em cuidadoras de seus filhos em tempo integral. A culpabilização dos indivíduos ou de grupos imediatamente próximos a situações de doença e morte é, como sugere Bastos, o lugar comum que oblitera as responsabilidades do Estado para a garantia de direitos, incluindo a promoção à saúde coletiva.

Contudo, o debate antropológico sobre a biossegurança emerge também da intersecção com os campos da ciência e da tecnologia e das relações humano-animal. O efeito imediato desse diálogo é o reposicionamento dos humanos na etnografia e o alargamento da noção de biopolítica. Por conseguinte, o próprio imaginário da biossegurança como trincheira que isola suas relações com outras espécies passa a ser tensionado. Não se trata, assim, de uma biopolítica pensada apenas em termos do controle e da produção da vida e dos corpos humanos, mas da interferência do Estado e de outros mecanismos reguladores das espécies animais, das plantas e dos microrganismos. Por diferentes vias, é o que nos mostram os demais trabalhos que compõem este número temático.

2 Ver, por exemplo, Ministro... (2016). 
$\mathrm{O}$ artigo de Rodrigo Charafeddine Bulamah, "Pode um porco falar?", por exemplo, combina etnografia e análise historiográfica para acompanhar a trajetória da introdução de porcos brancos no Haiti, após a peste suína africana-PSA. A PSA é uma doença que ameaçou criações em todos os continentes e foi o que justificou a erradicação da população local de porcos na ilha. A PSA mobilizou uma série de políticas e arranjos científicos que visaram contê-la, incluindo radicais mudanças na paisagem humano-animal. Mais do que isso, ela transformou o sistema - categoria que o autor traz do seu campo, como sendo uma operadora de um indício de diferença e de mudança de funcionamento com uma história específica. Nas suas palavras, a introdução dos "príncipes de quatro patas", como eram chamados localmente os porcos brancos introduzidos após o massacre daqueles locais, exigiu "técnicas, práticas e representações que constituem um conjunto de interações historicamente construídas". Na chave da antropologia da domesticação de Jean-Pierre Digard, os porcos brancos, para Bulamah, operaram com a população humana local um "sistema domesticatório", já que ambos se tornaram coconstrutores de representações, modos de ação, além da própria organização social.

A discussão que Bulamah traz, assim, nos auxilia a pensar no modo como políticas internacionais de biossegurança atuam localmente. Mas, também, nos permite perceber que elas não operam na simples chave da dominação ou imposição. Há resistência, e uma agenda local de significações e práticas passa a ser construída com os novos porcos, suas exigências materiais - alimentação, espaços, entre outros - e os protocolos sanitários anexados a eles. Por outro lado, é evidente que a introdução dos "príncipes de quatro patas" não responde apenas a uma preocupação sanitária internacional, mas a um projeto desenvolvimentista. Situação similar tem sido trabalhada por inúmeras etnografias dos artefatos tecnológicos. Nós temos em mente, por exemplo, o que Madeleine Akrich escreve sobre os kits de iluminação fotovoltaica na Costa do Marfim. Para Akrich (2014), uma descrição sociológica dos artefatos não deve levar em conta apenas a sua concepção ou projeto, mas o modo como assume formas nas práticas e relações, coproduzindo modos de ação e pensamento. O exemplo do kit da indústria francesa de fotocélulas é emblemático. A sua instalação era parte da promessa de melhoria estrutural para inúmeras comunidades sem luz. Contudo, as decisões começaram a ser pautadas a partir da perspectiva de investidores que decidiam quais regiões eram mais vantajosas 
em termos de desenvolvimento industrial e mercantil. Depois, os kits em si exigiam suprimentos e mão de obra francesa, já que os componentes e conhecimentos empregados na sua composição não coincidiam com as competências locais. Além disso, a distribuição dos aparelhos estava vinculada a indivíduos e suas propriedades, o que exigiu a reconfiguração das políticas locais de uso comum da terra e da própria noção de pessoa e coletividade. Em outros termos, não era apenas um artefato, mas um projeto desenvolvimentista europeu, com práticas, políticas e sentidos de mundo que era instalado na Costa do Marfim. Nas palavras de Akrich (2014, p. 161), "longe de representar mais que um apêndice sobre um dispositivo político preexistente, os objetos técnicos possuem um conteúdo político no sentido de que eles constituem os elementos ativos de organização das relações dos homens entre eles e com seu ambiente". Para resumir, no seu trabalho, Bulamah nos mostra como o porco é, também, objeto sociotécnico, que catalisa discursos, instituições e participa ativamente da definição de relações e representações.

Na sequência deste número temos o trabalho "Biosecurity and the ecologies of conservation", do antropólogo francês Frédéric Keck. O texto aborda um tema emergente no campo de discussões da biossegurança, que é o das sentinelas, a partir de uma etnografia das práticas de coleção entre caçadores de vírus e observadores de pássaros. Nas palavras de Keck, no artigo deste número, "o conceito de sentinela define aqui um território onde os sinais de futuras pandemias são capturados em animais para que o alarme seja disparado para os seres humanos" (tradução nossa). Exemplo disso são as recentes preocupações com macacos doentes com febre amarela, a observação de mudanças de comportamento em aves, mas também problemas com abelhas, plantas e criaturas marinhas, que passam a fornecer evidências que são convertidas em sinais de alerta sobre possíveis emergências de saúde, desastres ambientais ou mudanças climáticas (Segata, 2019).

No texto deste volume, particularmente, Keck se pergunta se os seres vivos são sentinelas uns dos outros tendo em mente três formas de atuação. Uma sentinela pode ser aquele animal que dá sinais como o caso do canário da mina de carvão, comumente empregado no século XIX. A presença de gases letais muitas vezes é imperceptível para os humanos, como é o caso do acúmulo de monóxido de carbono que resultava das explosões subterrâneas. Sensível ao aumento dos seus níveis, o canário morria, alertando que era preciso que os 
humanos saíssem em retirada. Mas a sentinela pode ser também um animal não vacinado em uma fazenda, como um porco, uma galinha ou uma vaca, que alerta o fazendeiro para a entrada de um vírus, adoecendo ou morrendo. Finalmente, células do nosso próprio organismo que alertam o sistema imune para que ele encontre respostas adequadas à presença de um desconhecido também são descritas como uma espécie de sentinelas. O autor critica o modo romantizado de se tratar os experts versados em virologia e imunologia que operam com sentinelas como se fossem xamãs de pandemias superestimando a ideia de preparação e resposta. Em vez disso, ele traça um paralelo entre os microbiólogos, os observadores de pássaros, mas também os antropólogos que trabalham em museus, para mostrar como "os seus raciocínios e práticas cinegéticas são comuns quando constroem reservas a conservação do passado e da imaginação do futuro" (tradução nossa).

Keck é uma figura central para pensar a constituição de uma antropologia da biossegurança. A sua trajetória nesse campo remonta ao grupo que reuniu Stephen Collier, Andrew Lakoff, Stephen Hinchliffe, Carlo Caduff, entre outros no Laboratório de Estudos do Contemporâneo, liderado por Paul Rabinow, em Berkeley. Como tratado anteriormente, um parte importante da agenda antropológica desse campo se desenhou lá. Foi nesse ínterim que Keck produziu um estudo sobre a gripe aviária em Hong Kong entre 2007 e 2009. Daquele trabalho resultou o livro Un monde grippé (Keck, 2010) - uma referência essencial para quem se interessa por antropologia das relações humano-animal, mas também sobre antropologia da ciência e, é claro, das práticas de biossegurança desde um ponto de vista etnográfico. Nele, o tema das sentinelas já apareceu de forma central. Ante o extermínio de milhões de aves na China, consideradas reservatório da Sars, controvérsias e polêmicas entre opinião pública, as autoridades sanitárias, os cientistas e ativistas da proteção animal ligados, sobretudo, ao budismo, emergiram e passaram a exigir alternativas para o controle sanitário. Além disso, o tratamento de certas espécies como reservatório de doença era, e ainda é, uma porta aberta para a estigmatização, especialmente em casos onde populações humanas, de porcos, galinhas e outros animais têm uma convivência bastante próxima. Razão pela qual, segunda a crítica de Frédéric Keck, "o povo asiático" seja frequentemente tratado "como reservatório de vírus".

O debate sobre os animais como sentinelas ofereceu, assim, um reposicionamento das relações de saúde/doença entre espécies, em uma esfera mais 
ampla do que aquela dos laboratórios e da pesquisa microbiológica. Mais recentemente, o autor também tem mostrado como esse processo passou a empregar um diálogo entre a ciência de laboratório e formas tradicionais de conhecimento. Como ele mostra em Avian reservoirs, seu mais recente livro, há hiatos e desencontros entre a codificação, a temporalidade e outras variantes dos sinais emitidos pelos animais que estão em ambientes controlados de laboratório e aqueles que estão "na vida selvagem". Para mitigar esses "problemas de comunicação", observadores de pássaros passam a partilhar as suas experiências com os experts da biossegurança. Aficionados pelas aves, esses observadores percebem, numa escala mais alargada de tempo como anos e décadas, mudanças sutis de comportamento desses animais que a pressa dos orçamentos e das respostas da pesquisa laboratorial para a biossegurança não permitem conhecer (Keck, 2020). Em outros termos, conhecimento sensível e experimental na ciência da preparação e resposta.

Mas, como mostra o artigo "Quando os biólogos olham para os bichos", de Elizeu Pinheiro da Cruz, também neste volume, as práticas de coleção não constituem somente inventários da vida convertidos em ferramentas da ciência, da educação, da fruição e da biossegurança. Elas fazem pesquisadores e situam suas biografias em espaços performados pela imaginação da ecologia moderna. ${ }^{3}$ Para tratar disto, o autor nos descreve as rotinas dos laboratórios de ciências biológicas e o modo como a biodiversidade da caatinga é permeada por relações tensas de vida e morte de animais. No seu argumento, essas relações vinculam animais a seus biólogos e suas carreiras conjuntas, desenhadas pelos limites do bioma. A ambiguidade exposta pelo autor é a de que a morte é convertida em inventário da vida na composição de coleções de referência. Ela é parte da mediação que conecta a caatinga com quem "está fora dela", sendo justificada como indicador de medidas de biossegurança e proteção daquele

3 A etnografia de Eduardo Neves Rocha de Brito, intitulada A caatinga dos biólogos e a política das plantas: controvérsias na transposição do Rio São Francisco, é particularmente esclarecedora sobre esse ponto. Em seu trabalho de campo, ele acompanhou a atuação de biólogos no projeto de transposição do rio São Francisco, mostrando como um imaginário de fronteiras do bioma era materializado em práticas e materialidades, como a de operar a limpeza dos pneus das máquinas para que não carregassem passivamente raízes. O objetivo era impedir que a caatinga fosse "contaminada" com plantas de outros ambientes (Brito, 2017). 
ambiente. Em jogo, está a ideia de que representação (por meio da morte) preserva "o original" (vivo). Nas palavras do autor,

animais não humanos são bons para trabalhar juntos como parceiros de descrições da biodiversidade pois colaboram com a elaboração da caatinga em indicadores de diversidade e ocorrência nas disciplinas científicas ecologia e zoologia. Traduzidos em laboratórios e museus, animais e biólogos circulam como diferenças em comunidades de prática (textuais e outras), informando a composição dos territórios que pesquisam e se firmando como testemunhas de um mundo sempre ameaçado pelos humanos.

A consideração de animais como parceiros é particularmente interessante para a antropologia em muitas direções. O trabalho de Frédéric Keck, por exemplo, já apontava para esse registro. A despeito do termo sentinela ainda ecoar a linguagem militar empregada nos contextos de atuação da biossegurança, ele opera uma mudança de sentido do animal. Em jogo, o deslocamento dele da posição de alvo a ser erradicado em virtude de ser um vetor ou um reservatório de agentes patógenos (como no conhecido caso dos mosquitos ou dos porcos crioulos descritos por Bulamah neste volume) para convertê-lo em uma espécie de parceiro vigilante nas políticas de saúde.

Crises sanitárias tensionam o debate político, moral e epistemológico que envolve animais, humanos, saúde e suas infraestruturas e ambientes. E esse é o caso do que aparece no artigo de Bernardo Lewgoy, Andrea Mastrangelo e Luiza Beck, "Tanatopolítica e biossegurança", e também naquele de Joana Cabral de Oliveira, "As vicissitudes do matar", que compõem este volume de Horizontes Antropológicos. Ambos tratam da leishmaniose - o primeiro, da visceral, o segundo, da tegumentar, e as críticas levantadas nestes trabalhos abrem pistas para pensar um processo multiespécie que questione a forma tradicional de descrever doenças vetoriais e antropozoonoses como contaminação de via de mão única de animais para humanos. Ou seja, saúde/doença como um lugar de mediação, de política e de biografia partilhada entre animais, humanos e ambientes.

No artigo de Lewgoy, Mastrangelo e Beck dois regimes de gestão da vida e da morte são postos em relevo a partir dos recentes sustos de leishmaniose visceral em Porto Alegre. Cães são tradicionalmente considerados os reservatórios do protozoário que provoca a doença, e as políticas vigentes sugerem 
a eutanásia desses animais como forma de controle sanitário. Acontece que essa prática tem sido cada vez mais questionada e condenada por inúmeros setores da sociedade - a destacar, os grupos de proteção animal e criadores - a partir da emergência de novas moralidades e direitos, especialmente em meios urbanos. Diferentemente de algumas outras espécies animais, como o caso de mosquitos e, em alguma medida, os ratos, que são frequentemente exterminados como meio de operar o controle sanitário, a morte de cães enseja protestos, dada a frequente extensão da humanidade sobre eles. Como escrevem os autores, "a eutanásia de cães pelo poder público é atravessada por tensões e dilemas entre a imposição higienista de uma ordem espacial-sanitária urbana e a crescente antropomorfização dos animais de companhia, os quais têm inspirado as modernas políticas de proteção de animais".

Em questionamento a essa política de biossegurança de ordem tanatológica, criadores e protecionistas passaram a judicializar os casos de tentativa de eutanásia profilática de cães, argumentando que alternativas para o tratamento da doença já têm sido desenvolvidas. É o caso de fármacos, como o Milteforan ${ }^{\circledR}$. Os autores mostram, a partir de um amplo apanhado de casos brasileiros, como decisões judiciais foram favoráveis à suspensão do extermínio de animais, considerando o fármaco como alternativa de cuidado e estendo aos cães argumentos de defesa do direito à vida. Em cena, "a premissa de que os direitos individuais - sejam de cães, sejam de veterinários e tutores - não podem sobrepor-se à proteção de saúde pública". Por outro lado, como mostram os autores, autoridades de saúde do setor público questionam essas decisões, considerando que a manutenção da vida de animais doentes é uma prática que oneraria ainda mais os cofres da saúde, já que esses novos medicamentos são considerados de alto custo.

Resulta disso que novos arranjos políticos ganham formato. Como mostram Lewgoy, Mastrangelo e Beck, inúmeros eventos como palestras, cursos e seminários sobre os benefícios do tratamento medicamentoso da leishmaniose têm se espalhado por toda a parte e se tornado cada vez mais frequentes. Na maioria dos casos, eles são patrocinados pela indústria farmacêutica e endossados por autoridades políticas que defendem a agenda protecionista animal. Assim, além da capitalização das novas moralidades da defesa animal o questionamento da tanatopolítica introduziu novos agentes e colocou em relevo outras estruturas de desigualdade, como é o caso da distinção entre pets e párias. No 
primeiro caso, cães, quase sempre de raça valorizada, que ocupam lugar estável nas relações domésticas; no segundo, cães de rua, em geral, sem raça e nem "dono". Nesse caso, como sugerem os autores,

o tratamento privado do animal cria duas lógicas oficiais de governo da vida para os cães diagnosticados com leishmaniose visceral. A primeira lógica é a continuidade da tanatopolítica das eutanásias aplicáveis a cães de rua, errantes, comunitários e pertencentes aos tutores pobres; a segunda, o tratamento com fármacos e serviços veterinários, acessível apenas para as pessoas que podem bancar os altos custos do tratamento.

Já o caso descrito por Joana Cabral de Oliveira, sobre a leishmaniose tegumentar na Terra Indígena Wajãpi (AP), aponta para outras formas de relação, igualmente instigantes para a antropologia, pois intersecta os interesses da antropologia da biossegurança com a etnologia indígena. Conforme descreve a autora, para estudar os determinantes socioambientais da doença que grassava na Terra Indígena, uma das ações dos epidemiologistas era a de capturar morcegos para analisar a presença de vírus em seu sangue. Outra era o emprego de armadilhas para a captura de flebotomíneos - conhecidos como "mosquito-palha", um dos principais transmissores da leishmaniose. Ao observarem essas práticas, algumas famílias wajãpi questionavam o porquê de não se matarem todos os morcegos em vez de soltá-los ou manter as armadilhas de capturas de mosquitos continuamente. Os cientistas então explicavam que o extermínio do morcego acarretaria desequilíbrio ambiental e que algumas armadilhas de estudo de mosquitos também não resolveriam o problema. Contudo, morcegos e mosquitos se alimentam com sangue e as narrativas wajãpi mostravam que isso os colocava em um outro registro - aqueles dos inimigos canibais, que precisavam ser exterminados (owapisipa). Assim, ainda que os cientistas propusessem uma ética moderadora, considerando que a morte de animais não resolveria o problema da leishmaniose, para os Wajãpi o problema posto não era a doença, mas as práticas daqueles animais e o tipo de relação que eles protagonizavam. Nas palavras da autora,

o que os Wajãpi pareciam desejar fazer com os seres hematófagos (ou seja, os morcegos e os flebótomos) era replicar a ação de extermínio tal qual 
empreendida em tempos anteriores com alguns inimigos. Enquanto uma versão transformada dos inimigos canibais, os hematófagos exigem e são passíveis de uma ação de mesma ordem: owapisipa.

A matabilidade de alguns seres, as relações com diferentes níveis de alteridade e as perspectivas das relações interespecíficas são trazidas pela autora para mostrar como eventos de acordo e desacordo entre alguns Wajãpi e a equipe de cientistas operavam não apenas diferentes entendimentos sobre a relação saúde/doença e suas mecânicas reconhecíveis, mas um encontro de ontologias.

A formulação de arranjos de espécies amigas e inimigas evocam comparações e simetrizações que nos ajudam a complexificar o debate sobre como a biossegurança, pensada a partir de um cenário de mundo, ergue suas fronteiras. É o caso também da temática das espécies invasoras, trazido por Caetano Sordi neste número de Horizontes Antropológicos no artigo "Mobilização e predação". A partir de uma longa experiência etnográfica com o manejo de javalis asselvajados no pampa brasileiro, o autor tensiona a relação entre espécies tal como formulada a partir da linguagem da guerra. Em particular, ele questiona o imaginário das invasões biológicas a partir de um exercício de simetrização entre duas perspectivas distintas: a mobilização, que ecoa "a aplicação de um pensamento estatal, territorial e exclusional, para se conceber o conflito com outras espécies" e a predação, caracterizada pela "incorporação do inimigo e sua potência como forma de garantir a vitalidade do grupo".

A mobilização, como argumenta Sordi, faz referência às noções de guerra que derivam de um imaginário ambiental moderno bastante específico, que ele classifica com sendo vestfaliano e clausewitziano. O primeiro acentua a preeminência da soberania nacional e do respeito pelas fronteiras territoriais; o segundo destaca a importância da resposta violenta às ameaças externas, "a partir de um esforço de mobilização entre população e aparelho estatal". Esse tipo de enquadramento pode ser notado em exemplos trazidos por Sordi, como aqueles das audiências públicas em torno do manejo do javali que o inscrevem como uma genuína "máquina de guerra" em pleno ataque a indefesos agricultores. Segundo autor, essa é razão pela qual se demandaria a liberação de armas de calibre mais grosso para o abate do animal. Uma resposta violenta que não apenas reforça a sua tese de mobilização, mas que também pode operar como uma "caixa de ressonância" de outros conflitos colocados em relevo 
na sociedade brasileira, relacionados, sobremaneira, ao "advento de uma nova hegemonia conservadora no país, simbolicamente sustentada sobre o 'direito de autodefesa' e o ruralismo".

A predação, por outro lado, apela ao paradigma inclusional amplamente característico do pensamento ameríndio que acentua a incorporação do inimigo e da sua potência como forma de garantia da vitalidade do grupo. Seguindo esse caminho, o autor traz importantes evidências etnográficas de como o javali produz uma espécie de solidariedade entre agricultores e pecuaristas para quem o animal encarna a figura, odiada em ambos os lados da fronteira Brasil-Uruguai, do abigeatário - o ladrão de gado. Nesse caso, mais do que uma relação belicosa, os encontros humano-javali passam a ser tensionados pelo respeito à propriedade e à honra, "na qual a questão da vingança e da desforra moral era mais importante que qualquer conotação nacionalista ou patriótica dessa 'guerra"'. Resultava disso que o javali não era apenas capturado e abatido, mas consumido, como uma forma de quitação de dívidas. Daí de se pensar que políticas de biossegurança também são reconfiguradas localmente num ajuste que vai da exclusão às formas de incorporação das partes.

As formas de intervenção na autonomia alimentar de certas populações é outro objeto importante das críticas do universo da biossegurança. Neste número, ele é discutido no artigo de Rosângela Pezza Cintrão e Leonardo Vilaça Dupin, intitulado "Microbiopolítica e regulação sanitária". Os autores analisam a relação entre a produção local de queijo artesanal, em Minas Gerais, com as imposições da regulação sanitária conformada pelos parâmetros internacionais da biossegurança. O foco é o modo como essas políticas se associam a conglomerados de mercados produzindo uma imagem distorcida de que queijos produzidos na roça são atrasados e anti-higiênicos, enquanto aqueles que atendem aos moldes industriais são puros e seguros.

A biossegurança como moralizadora das relações entre humanos e seres microscópios é baseada no que a antropóloga Heather Paxson (2008) chamou de sonho hiper-higiênico dos pasteurianos. Nas suas palavras (Paxson, 2008, p. 16-17, tradução nossa, grifo nosso):

Se Michel Foucault argumentou que o século XIX viu o surgimento da biopolítica por meio de formas de governar a vida das pessoas, particularmente, via controle dos corpos com a punição do sexo e da reprodução, Bruno Latour, ao 
analisar o trabalho de Louis Pasteur, rastreia uma história paralela, descrevendo o alojamento da vida microbiana na própria constituição do campo social. Os micróbios revelados por Pasteur passam a ser controlados pelos higienistas, funcionários do governo e os economistas, que assentaram as bases para o que eles acreditavam ser relações sociais "puras" - ou seja, relações que não seriam descarriladas por irrupções microbianas, que poderiam ser preditas e, portanto, racionalmente ordenadas. A biopolítica, então, é acompanhada pela microbiopolítica: a criação de categorias de agentes biológicos microscópicos, a avaliação antropocêntrica desses agentes e a elaboração de comportamentos humanos adequados vis-à-vis microrganismos envolvidos em infecções e inoculações ou na digestão. As práticas pasteurianas configuraram os micróbios como elementos a serem eliminados para que as políticas humanas pudessem ser cultivadas.

Como Cintrão e Dupin, Paxson $(2008,2013)$ também estudou a produção de queijos de leite cru. Ambos os trabalhos mostram como um ethos pós-pasteuriano das culturas de queijo artesanal reconhece que os micróbios são onipresentes, necessários e, de fato, saborosos. Mais que isso, o queijo artesanal é uma peça fundamental para a constituição de identidade e práticas, já que é amplamente enredado em economias de escala e ligado à agropolítica e sua conexão com o local.

A crítica que essas etnografias sobre o queijo nos trazem é a de que a medicalização dos alimentos sob a forma de segurança alimentar não altera apenas esses produtos, mas os sentidos de si e de mundo dos seus produtores. Além disso, estes trabalhos nos ajudam a perceber a atuação política de práticas alimentares artesanais, que investem tanto nas potencialidades colaborativas culturalmente situadas como na positividade dos arranjos entre humanos e vidas microscópicas. Micróbios ajudam a formar tradições culturais e paisagens agrárias (como no caso do terroir, por exemplo), e criam novas alianças entre fabricantes de queijos, agricultores, cientistas, comerciantes e gourmets. Por outro lado, algumas das políticas sanitárias sustentadas pelo paradigma do pasteurianismo cria cidadãos com expectativa de que o Estado assegure um abastecimento seguro de alimentos (Paxson, 2008). Esse processo é fingido pervasivamente na associação entre as agências de promoção de biossegurança e aquelas de mercado de grande escala, com a promoção de espaços supostamente assépticos e controlados, como aquele dos ambientes industriais. 
Cabe também expressar que, desde o início deste ano de 2020, a pandemia de Covid-19 tem produzido impactos sem precedentes na ordem biomédica e epidemiológica, mas também social, econômica, política, cultural e histórica. O conhecimento da doença, suas formas de mitigação e controle e seus inúmeros efeitos nos corpos, nas subjetividades e nas biografias de quem têm experimentado a pandemia ainda são uma questão em aberto - e também um desafio à nossa disciplina. A elaboração deste número de Horizontes Antropológicos foi fortemente afetada por este cenário, dada a convergência do seu tema com a pandemia. Assim, no Espaço Aberto, as perdas, os conflitos, o sofrimento e as incertezas produzidas em meio à pandemia da Covid-19 também ajudarão a formar um solo fértil para materializar a abertura de alguns eixos de discussão sobre o tema da biossegurança na antropologia. No trabalho, intitulado "Covid-19, biossegurança e antropologia", Jean Segata reage a pontos destacados do desenvolvimento inicial da pandemia para elaborar um estado da arte da biossegurança que situa alguns dos seus quadros mais gerais, como também seus expoentes e tendências. Não se trata de uma análise epistemológica densa ou um painel histórico amplo, mas de um breve destaque de algumas linhas de pesquisa que mais têm circulado nos debates atuais desse campo. Na sequência, a ênfase se dá no imaginário de assepsia e contenção e nas chamadas novas inteligências epidêmicas, presentes de forma robusta no seu universo atual. O intuito é apresentá-los, mas também pensar com eles a constituição de um debate antropológico sobre a pandemia, a biossegurança, seus desdobramentos e pontos de crítica na antropologia.

Ainda na seção Espaço Aberto, Ruben George Oliven e Pedro de Moraes Garcez entrevistam a antropóloga canadense Monica Heller, professora da University of Toronto e ex-presidente da Associação Norte-Americana de Antropologia. Nela, Heller nos mostra como aspectos de sua vida e formação acadêmica cruzam caminhos para torná-la uma das principais referências no campo da antropologia linguística. Para ela, o fato de crescido em Montreal - uma cidade, nas suas palavras, "multilíngue, dividida principalmente entre inglês e francês, com uma longa história de colonialismo" - ter seguido para Berkeley, depois para a França e para Toronto, "rival" de sua cidade natal, pesou nas suas escolhas de pesquisa, que incluem Estados-nação, desigualdade social, colonialismo e globalização. No encalço disso, temos a oportunidade de conhecer as orientações e interesses intelectuais que conformaram alguns dos 
departamentos de antropologia, sociologia e linguística dos Estados Unidos e Canadá da segunda metade do século XX, e como eles produziram efeitos nos debates que ganharam a cena internacional nesse período.

Por fim, a foto que ilustra a capa deste número de Horizontes Antropológicos foi tirada por Jean Segata, em fevereiro de 2018, no Hospital Piñero, em Flores, Buenos Aires. Trata-se da porta de um espaço destinado ao armazenamento e descarte de resíduos hospitalares potencialmente contaminantes. Na época, nós fazíamos trabalho de campo juntos, acompanhando agentes do Instituto de Zoonoses Luis Pasteur em suas "caçadas ao mosquito". ${ }^{4}$ O hospital passava por inúmeras reformas naquele verão, algumas das quais para atender às atualizações das normas sanitárias e de segurança predial. Trabalhadores da obra denunciavam que o pátio havia se tornado um criadouro do Aedes aegypti e, assim, um possível foco da dengue que já preocupava a cidade, desde o surto de 2016.

Contudo, como notávamos, não era apenas a reforma e seus entulhos que traziam desafios à contenção da doença. Alguns dos hospitais de Buenos Aires foram erguidos no fim do século XIX. O modelo de pavilhão - com jardim interno, flores, árvores, fonte de água corrente e valorização dos espaços arejados - era embebido de um imaginário de conversão da natureza em conforto e terapêutica. É que no tempo dos miasmas, "o higienismo incorporou a noção de verde como instrumento sanador da urbe" (Campari, 2018, p. 63, tradução nossa). Mas aquela arquitetura orientada para a regeneração favorece hoje a criação de mosquitos e atrapalha os modelos baseados em controle vetorial. Nos jardins e fontes, os mosquitos também encontram lugar. O tempo das pestes e do sofrimento nem sempre coincide com aquele dos sentidos, das práticas, da ciência, da burocracia e da justiça e seus artefatos. Em outros termos, as materialidades da transmissão duram mais do que os seus paradigmas. Assim, se as atuais políticas de biossegurança prometem, quase sempre, preparação e resposta para o que ainda virá, resta saber o que permanecerá delas depois que o seu futuro imaginado passar.

4 O projeto, intitulado "La antropología y las emergencias sanitarias urbanas" foi apoiado pelo Consejo Nacional de Investigaciones Científicas y Técnicas (CONICET), no contexto do Programa Salud, Ambiente y Trabajo - 211, dos Proyectos de Desarrollo Tecnológico y Social - PDTS (2017-2019). 


\section{Referências}

AKRICH, M. Como descrever os objetos técnicos?. Boletim Campineiro de Geografia, Campinas, v. 4, n. 1, p. 161-183, 2014.

BINGHAM, N.; HINCHLIFFE, S. Mapping the multiplicities of biosecurity. In: COLLIER, S.; LAKOFF, A. (ed.). Biosecurity interventions: global health and security in question. New York: Columbia University Press, 2008. p. 173-194.

BRITO, E. N. R. de. A caatinga dos biólogos e a política das plantas: controvérsias na transposição do Rio São Francisco. 2017. Dissertação (Mestrado em Antropologia Social) - Centro de Ciências Humanas, Letras e Artes, Universidade Federal do Rio Grande do Norte, Natal, 2017.

CAMPARI, G. Paisajes sensibles: subjetividades, salud y patrimonio en el espacio verde intrahospitalario. Buenos Aires: Prometeo Libros, 2018.

COLLIER, S.; LAKOFF, A. The problem of securing health: mapping the multiplicities of biosecurity. In: COLLIER, S.; LAKOFF, A. (ed.). Biosecurity interventions: global health and security in question. New York: Columbia University Press, 2008. p. 7-32.

DINIZ, D. Zika virus and women. Cadernos de Saúde Pública, Rio de Janeiro, v. 32, n. 5, p. 1-4, 2016 a.

DINIZ, D. Zika: do sertão nordestino à ameaça global. Rio de Janeiro: Civilização Brasileira, 2016b.

DINIZ, D. Zika in Brazil: women and children at the center of the epidemic. Brasília: Letras Livres, 2017.

FIDLER, D.; GOSTIN, L. Biosecurity in the global age. Stanford: Stanford University Press, 2008.

KECK, F. Un monde grippé. Paris: Flammarion, 2010.

KECK, F. Avian reservoirs: virus hunters and birdwatchers in Chinese sentinel posts. Durham: Duke University Press, 2020.

LÖWY, I. Vírus, mosquitos e modernidade: a febre amarela no Brasil entre ciência e política. Rio de Janeiro: Editora Fiocruz, 2006.

MINISTRO da Saúde volta a dar declarações polêmicas sobre o Aedes aegypti. Época, 26 jan. 2016. Disponível em: https://epoca.globo.com/tempo/filtro/noticia/2016/01/ ministro-da-saude-volta-dar-declaracoes-polemicas-sobre-o-aedes-aegypti.html. Acesso em: 27 abr. 2020. 
NEVES, T. P. et al. O conceito de biossegurança à luz da ciência pós-normal: avanços e perspectivas para a saúde coletiva. Saúde e Sociedade, São Paulo, v. 16, n. 3, p. 158-168, 2007.

PAXSON, H. Post-Pasteurian cultures: the microbiopolitics of raw-milk cheese in the United States. Cultural Anthropology, Arlington, v. 23, n. 1, p. 15-47, 2008.

PAXSON, H. The life of cheese: crafting food and value in America. Oakland: University of California Press, 2013.

SEGATA, J. El mosquito-oráculo y otras tecnologías. Tabula Rasa, Bogotá, v. 32, p. 103$125,2019$. 